Article type: Original Article

Corresponding author mail id: miriancalvo@gmail.com

\title{
Reflective Drawing as a Tool for Reflection in Design Research
}

Mirian Calvo

Abstract:

This paper explores the role of drawing as a tool for reflection. It reports on a $\mathrm{PhD}$ research project that aims to identify and analyse the value that co-design processes can bring to participants and their communities. The research is associated with 'Leapfrog', a three-year project funded by the Arts and Humanities Research Council (AHRC). It aims to transform public engagement through activating participation using co-design practices. The paper reports on the analysis of initial research findings arising from a series of workshops with members of non-profit organisations on the Isle of Mull, in the Highlands and Islands of Scotland, in which co-design practices were used. The paper reflects on the use of drawing used as a tool to capture the author's reflections and her own personal development as a researcher. In this study the term reflective drawing refers to the use of drawing as a tool to support the research reflection process within an ethnographic approach to the fieldwork. Reflective drawing is used in two different stages of the reflection process: (i) to record data during fieldwork enabling reflection-in-action, complementing field notes and disclosing visual and kinaesthetic learning; and (ii) to recall lived experience during the reflection sessions conducted after the observed activity, which helps to establish a bridge between theory and practice. Reflection is defined as an intuitive 
process that enables the understanding of oneself within a context of practice. Hence, understanding reflective drawing requires exploration of the reflection process. Keywords: Reflective drawing, co-design, design ethnography, reflective practice, autobiographical research, socially active design.

This paper outlines a $\mathrm{PhD}$ research project associated with Leapfrog, a three-year, $£ 1.2$ million AHRC-funded project led by Lancaster University and co-hosted by the Glasgow School of Art, and other public sector and community partners. Central to this paper is the research question: How can drawing embed and complement the reflection process in design research? Focused on transforming public engagement, the Leapfrog project aims to develop innovative ways for citizens' voices to be heard on issues close to the heart of their communities. This paper articulates a process of collectively involving communities in the design and development of engagement tools that can then be taken back into communities to support effective citizenship participation. Co-design, in this way, is used to bring people together from different backgrounds and levels of expertise, to engage in collective dialogue in order to enact transformative agency in community engagement.

The PhD research associated with Leapfrog aims to understand how co-design can be used as a vehicle to promote social change, in addition to understanding some of the processes, including informal learning, that co-design ignites. A pilot study was conducted over six months on the Isle of Mull in the Highlands and Islands of Scotland and involved a series of workshops in which a range of stakeholders participated. The pilot focused on the co-construction of knowledge and development of shared meanings around issues of central concern to community participants. Drawing, combined with field notes, was used as a tool to elicit, gather and articulate these concerns during the workshops. These documents were then translated into tangible 'solutions' or artefacts - engagement tools - that could be used to support wider community engagement. Drawing was also used as a personal reflective tool, 
as a way for me to understand the context and the activities within it. Therefore, the aim in this paper is to discuss the role of drawing and its use as a tool to support thinking and reflection from a design practitioner as well as a researcher perspective. Hence, it seeks to explore the ways in which drawing can be used as a potentially powerful method to support reflective learning for both participants and researchers.

\section{Cultural-Historical Activity Theory (CHAT) as the theoretical} framework

In this work I combined an ethnographic approach with the overarching research framework of my $\mathrm{PhD}$ : CHAT. Other theories including Communities of Practice (CoP) were also used. I have aimed to develop a holistic approach for studying codesign and revealing informal learning processes. CHAT is applied in the reflections as the lens through which to make sense of the complexity and uncertainty of the field. In this regard, CHAT helps me to identify the key components and interdependent relationships. For example, unveiling synergistic processes of interaction (human-human and human-tools), and eliciting awareness of informal learning. On the other hand, the ethnographic approach has helped me to gather insights about the reasoning of some of the participants, and their motivations to come and participate, as well as helping me to reflect on my own role. This was done by focusing on participants, and afterwards interpreting the data from their activities using the CHAT unit of analysis (see Engeström 1987, 78). 


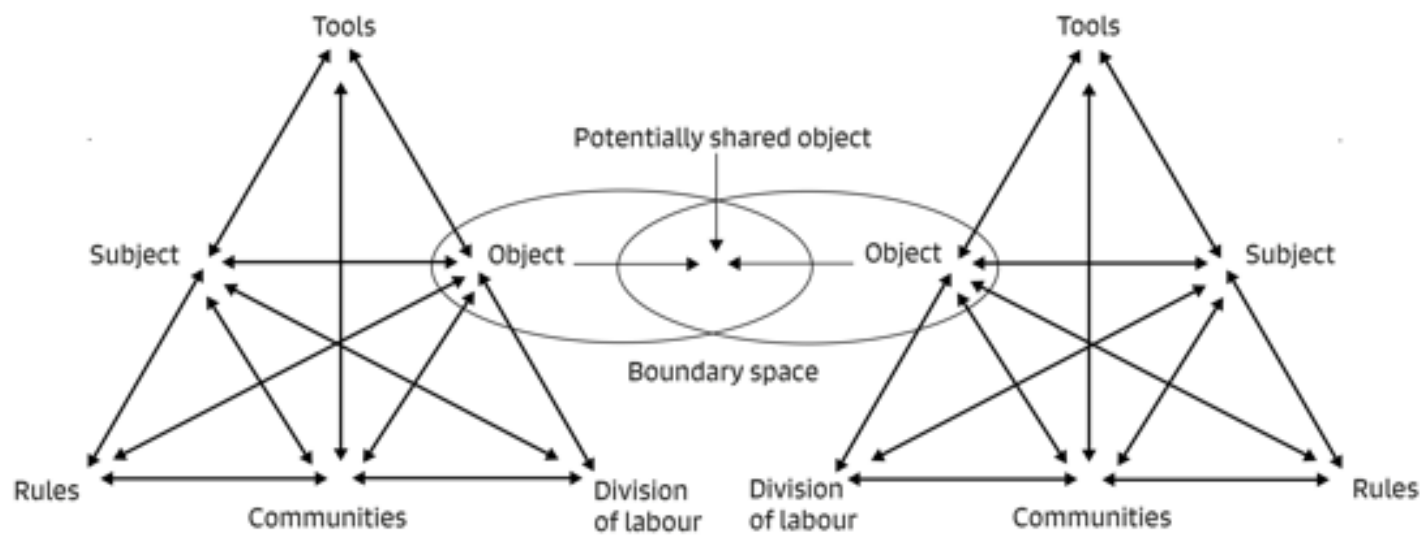

Figure 1. CHAT Unit of Analysis. Reinterpretation from Engeström's diagram $(1987,78)$.

CHAT is a multidisciplinary framework that focuses on the study of human agency from both individual and social perspectives. CHAT understands people as social beings, and consciousness as part of our social nature. Ryder (2013) observes that human activities are governed by cultural standards that society establishes. That is why Engeström (1987) modified Vygotsky's unit of analysis to include the community, rules and the division of labour. In this model, tools mediate between the subject (participant) and the object (motivation, purpose, or goal) of activities. Rules mediate between the subject and the community, and the division of labour mediates between the community and the object. Here, the term community aligns with the communities of practice, as defined by Wenger (1998): a group of people who engage in an activity driven by shared motivations and goals, which entails a process of collective (informal) learning by participating in a sociocultural context of practice. In relation to this, learning might viewed as the shared motivation to bring people together or it might be an unintended outcome. The division of labour illustrates the division of roles and the power dynamics between stakeholders.

Within this research, 'engagement tools', which are often the products of the codesign process, are the artefacts that individuals use in the engagement process with members of their community (practitioners, researchers, designers or non-designers involved in community engagement). Such tools help us to engage in telling, making 
and enacting (Brandt et al. 2013). The concept of (engagement) tools was developed in the 1980s-1990s in the tradition of system design (Andersen et al. 1990), when Participatory Design acquired a leading role as an approach for developing cooperation in the design of information technology systems (Blomberg and Karasti 2013), involving users, anthropologists and developers. Engagement tools differ from 'cultural probes' (Gaver et al. 2004) - which are provocative artefacts that aim to inspire design ideas from the responses of people. 'Cultural probes' afford one-way communication, hindering (informal)-mutual learning (Blomberg \& Karasti 2013); instead, engagement tools aim to establish two-way communication, open for input and debate, and to facilitate enriched dialogues on issues close to the heart of the communities.

In line with CHAT principles, this work defines tools as artefacts or processes that mediate in human activity and aid in the achievement of human objectives - which in the pilot study was community engagement. As Vygotsky (1978) argues, human agency is mediated by its context; hence cultural mediation intervenes in the formation of higher psychological configurations such as artistic activities and in the co-design of tools. Lektorsky (2009) added the observation that human-made tools such as language, signs and drawing, mediate communication between individuals. Here drawing is seen as a human tool of expression that enables interaction. Kuutti (2001) notes that any activity implies interaction with tools, ranging from methods to physical objects. On this matter, Er (2014) contends that tools have the ability to guide those who use them but that they also influence the manner in which people approach such activity. Here the question arises: did the activity develop first, followed by the tools, or vice-versa? To my understanding, they co-evolve. In this research, the interest in engagement tools has a twofold focus: firstly, on their ability to empower users and simultaneously, by restricting certain actions, focusing and producing efficacy; secondly, they become the products of the co-design process. In the Leapfrog project, the products are engagement tools - which are co-designed with 
local communities (of practice) concerned with a shared problématique. The tools are co-created and prototyped in a concrete context and then, we disseminate them to a wider audience to observe whether other communities with a different problématique can use the tools, adapting or appropriating them in various ways.

\section{A pilot study on the Isle of Mull}

The fieldwork for this $\mathrm{PhD}$, which was associated with one of the main Leapfrog research projects, was conducted on the Isle of Mull with participants drawn from five different non-profit organisations operating on the island Highlands and Islands Enterprise (HIE), Mull and Iona Community Trust (MICT), Wild Mull (WM), Ulva School Community Association (USCA) and Tobermory Harbour Association (THA). Participants came together and participated in several community workshops. They participated in the project hoping to learn from one another's experience of community engagement, and to collectively develop engagement tools to support engagement activities within their respective communities. This opportunity enabled me to introduce myself to these communities in the role of participant-observer. Participant observation is an ethnographic role that can be taken into the field (Junker 1960), that generates scenarios whereby the researcher gains a unique perspective in understanding the sociocultural context (Labaree 2002).

The fieldwork adopted a design ethnography approach, where I took the role of 'insider-outsider' researcher. Such a position is understood as 'a third space, a space between, a space of paradox, ambiguity, and ambivalence, as well as conjunction and disjunction' (Corbin Dwyer \& Buckle 2009, 60). This role recognises that myself, as a researcher, will never be a complete insider because my perspective is being shaped by my lived experience and by my position in the research. This role enables me to locate myself as a third party observer, and to form a non-biased opinion about the observations (Hammersley \& Atkinson 1995). Design ethnography comes close to traditional ethnography, but draws attention to the wide patterns of daily existence 
relevant particularly for idea generation, and the designing and developing of a specific outcome (Salvador et al. 1999). It is about understanding the context of research through the observation of people in their natural settings, enabling the development of a holistic account. In this case, drawing was used to understand the dynamics of the various settings. Here the term 'context' covers a wide range of elements - people, communities, organisations, historical, sociocultural and political factors, alongside geographic and (physical) environmental conditions - 'that influence the behaviour and beliefs of individuals' (LeCompte \& Schensul 1999, 19). In ethnography, reflection and reconstruction are embedded in the practice as a way to assemble a rationale of inquiry. 'By including our role within the research, and (...) systematically exploiting our participation in the settings (...), we can produce accounts of the social world and justify them' (Hammersley \& Atkinson 1995, 21). I also used Grounded Theory as the theoretical framework. Grounded Theory relies on the principle that everything is continually changing and therefore nothing can be predetermined because people have the means to respond to changing contextual factors (Corbin \& Strauss, 1990). This enables the context to be the source of knowledge that emerges from practice.

I undertook four visits to Mull over six months, and these visits helped to structure the pilot study in four phases: co-design, the context, delivery and follow up. In the first phase, I participated in two co-design workshops facilitated by the Leapfrog team. Six participants from three organisations (MICT, WM and USCA) turned out to the first workshop. The first part consisted of analysing the participants' conflicts/barriers in their local contexts. All the participants were involved; they occupied different roles (project managers, volunteers and board of directors), in community organisations with different focuses. For example, MICT is devoted to enhancing the quality of life of the islanders. It functions as an organisational umbrella for several small non-profit organisations by providing them with advice, facilities and resources such as community workers, who mediate in community development projects. We all 
negotiated and reached agreement on the focus of the second workshop: improving community engagement, on how to reach more people - people who do not engage in their communities. Therefore, the themes were: young locals, rapid tools and planning event tools. Five participants turned out in the second co-design workshop. We worked in small groups on the idea generation of concepts for 'engagement tools' based on these themes. I co-designed with a new participant, who understood what the activity was about after I presented a few examples of how it could be an engagement tool. Here, we used drawing as a tool to elicit, gather and articulate these concerns into tangible engagement tools - providing solutions.

The second phase consisted of a tour around the island in order to gather a descriptive account of what it is like to live there. This time the trip was on my own and I adopted the role of a tourist-explorer. This took two days and I had the chance to experience at first hand the isolation among such communities. This isolation shapes the lifestyle and makes the residents develop a strong bond with the place. Here, I used reflective drawing to enable reflection-in-action, capturing my insights and documenting the travel. I also conducted an interview with one of the participants from the workshops.

In my third visit, I went back to participate in the 'Tool Sharing Event', also facilitated by Leapfrog. We brought the prototypes with us, that we had designed and based on the concept ideas from the first visit, giving them to the participants. This event elicited dialogues around their efficacy and usability, and also fostered the coconstruction of new knowledge emerging from sharing creative thinking. I also conducted interviews and I was invited to collaborate in a consultation event with one of the participants. The event consisted of the inauguration of a coastal path developed by her organisation (THA), and she thought that it would be a good moment to start engaging with several communities that live in Tobermory, the biggest village on Mull. This experience involved me in working closely with this participant to help undertake public consultation. It enabled me to holistically 
observe how the participant interacted with other people, to empathise with her moods, stresses, fears and body language. I used field notes and took pictures during the event, which I used later in my reflection session as a way to recall the experience. I used reflective drawing as a way to reconstruct the fragments and unveil interactional synergies. The objective was to understand the individual and collective contextual factors which play out simultaneously.

Finally, the last visit was an invitation from one participant (USCA) to stay in her community for a short period with the intention of forming insights around their context, and to better understand their concerns around community engagement. We went to see the community projects they were developing. For instance, a pontoon at the harbour that crosses to the Isle of Ulva. She said: "Another thing we are doing is putting into the water a pontoon for the boats to come and tie up. (...) We will need somebody to be a pontoon manager to collect the money, so this is another job'. I realised that the issue was not one of engaging people; it was more about re-engaging them. Some of the people I met had been involved in community engagement, but they became exasperated and disaffected, so they lost interest. It was about rebuilding the trust and finding innovative engagement tools that might transform perceptions and hence, community engagement.

\section{Key Concepts:}

\subsection{What is drawing?}

This research understands human beings as minded, emotional and embodied entities. Goethe states: 'the hands want to see, the eyes want to caress' (in Hodge 1998, 130). According to Pallasmaa (2009), our senses are the link with the outside world and our consciousness is both sensory and corporeal. These traditionally separated parts are actually indivisible; they have the same nature, the human body. Thus, our senses and muscles are more than receptors of stimuli. They are involved in the process of knowing and hence are a primary source of knowledge production. For instance, 
'intelligent hands' (Pallasmaa 2017, 101) comprehend the physicality of an abstract idea and materialise it into a concrete thing. As Frenhofer (in Toadvine \& Lawlor 2007) argues, 'A hand is not simply part of the body, but the expression and continuation of a thought which must be captured and conveyed...' (78). Indeed, the interconnectivity between the hand and the mind is crucial to understanding the concept of drawing. Humphrey (1998) chronicles how a five-year-old child, asked to explain how to draw, replied: 'I have a think, and then draw my think' (172). The lucid child's definition of drawing - combines thinking, intention and the action itself.

Humphrey (1998) compares the cave drawings made 30,000 years ago by our ancestors at the Chauvet cave with the drawings made by a three-year-old autistic girl called Nadia (see Selfe 1977, 1983, 1985). He concludes that the similarities between the drawings, in style and content, can be interpreted as evidence that drawing is a human ability that stems from a pre-modern mind - unable to perceive the elements within the context (Frith \& Happé 1994). In another study, Mithen (1996) suggests that drawing originates as a tool of human expression that emerges to mediate in the process of understanding the physical and natural environment. Conversely, he notes, language arises from the need to maintain interpersonal relationships (as Dunbar 1996). Consequently, language was a social tool for naming, and drawing expressed the context. The interest here draws on human beings interacting with the environment, using different thinking tools to suggest our psychological productions and therefore generate our own realities. These thinking tools, Dennett (2013) explains, co-evolved alongside our minds, making us smarter.

According to Humphrey (1998), in the evolution of the human mind, drawing was undermined as language developed. He suggests: 'Maybe, in the end, the loss of naturalistic painting was the price that had to be paid for the coming of poetry' (176). This draws attention to the nature of drawing, which I perceive as an act, a tool and an 
object. In this research, drawing is used as a tool to mediate with the context. The act of drawing enables reflective learning and when it is finished, it becomes simultaneously data for analysis and an object, which can elicit collective conversations. Here, drawing is understood as a human thinking tool, which entails a dialectical (two-way) communication between the mind and the hand, from the thought to the materialisation, and back.

\subsection{Co-design and the shift in design research}

Since the early 1970s, there have been calls to consider other ways of designing (Sanders \& Stappers 2008). According to Cross (1972), traditional design characterises itself as excluding people from any kind of creative process and, therefore, fails to address the complexity of current challenges. At the turn of the $21^{\text {s }}$ century, these challenges have different natures: environmental sustainability, cutbacks in public services, increasing social inequalities, privatisation of education and health care (Silverman \& Patterson 2015) etc. All act simultaneously in our everyday lives, constraining our possibilities to choose based on our needs. In relation to this, design research increasingly concentrates on identifying ways in which design can function as an activator of change, shifting from design driven by the market to design motivated by social claims. So-called 'socially active design' foregrounds society and its transformation, seeking sustainable approaches to living 'by acquiring new awareness and perceptions, by generating new solutions, activating new behavioural patterns and, hence, cultural change' (Fuad-Luke 2009, 78).

Co-design is increasingly being used in the voluntary sector, aiming at confronting societal issues due to its democratic and open design process (Fuad-Luke 2009). 'By co-design we indicate collective creativity as it is applied across the whole span of a design process' (Sanders \& Stappers 2008, 6). The term 'co-design' becomes an umbrella that covers a myriad of approaches such as social design, participatory design, meta-design, co-creation etc. (Fuad-Luke 2009). It is based upon the following principles: (i) people involved, knowingly or unknowingly, in the 
development of a design have the right to raise their voices and intervene in the design process (Carroll 2006); (ii) it encourages an interdisciplinary and multi-actor framework that collectively draws attention to the context of research (Fuad-Luke 2009); (iii) it aims to question the traditional hierarchies of power and inclusiveness (Broadbent 2003); (iv) it requires informal learning, called 'mutual learning' by FuadLuke (2009, 147); and (v) it needs the setting of a boundary space (Calvo et al. 2016; Edwards 2011) which is also referred to as a 'third space' (Gutiérrez 2008) in which the abstract and concrete spaces (Lefebvre 2003) can converge (Lee 2007). This turns into a powerful insight-generating approach which enables designers to co-construct with people. Underlining the premise that creativity resides in everyone, it has become a prominent key in innovation studies (Bason 2010). According to Cruickshank et al. (2012), innovation is understood as a systemic process requiring collective and creative activities performed by interdisciplinary expertise that emphasises knowledge-exchange amongst participants and disciplines. To consolidate such a knowledge-exchange Collier and Williams (2013) suggest the use of reflection as a bridge between what we learn and what we experience in the community.

\subsection{Reflective practice \& autobiographical research}

Schön (1987) introduces the notion of reflective practice as the activity that enables practitioners to become aware of the learning and construction of knowledge, which flourishes from lived experience. He subscribes to Dewey's (1925) notion of a designer as someone able to transform uncertain and complex situations into more concrete ones. Here, the role of analysis and criticism become essential dimensions within the design process. Designing leads to the reconstruction of a new perspective through 'a reflective conversation with the materials of a situation' (Schön 1987, 42). Thus, reflection is embedded in the designing process through the iterations of what is being designed. Furthermore, the iterative process entails drawing and re-drawing, helping to redefine and materialise ideas and thoughts. If we accept the idea of 
drawing as a thinking tool for grasping the physical environment, we can also see it as a tool for transforming it.

Reflecting on my drawing process within this research, I noticed that I draw in order to facilitate my reflections. When I draw, simultaneously, I think, recall and reconstruct my lived experience. Drawing is used as a tool to support reflective learning arising from the rationalisation of a handful of fragments shaped by my biography. This reflective process enables me to chronicle a meaningful story, as Formenti (2014) states:

One story leads to another, and this is all we know. Our sense of identity, mental wellbeing, trust and creativity depends on them. Until we are able to compose a shape, a meaningful story, out of the fragments we have, we cannot keep on keeping on, at least in any meaningful way (139).

This statement emphasises the reconstruction of lived experience, using autobiographical research, as a way to give sense to my personal story - merging past, present and future. This helps me to articulate my identity and positioning myself, as a researcher, within the research.

\subsection{Developing as a reflective practitioner}

My life has undergone many changes over the last decade. I was an architect and urban designer working between research and practice, shaping public spaces, and I firmly believed that the work I was engaged in would end up positively impacting on the lives of citizens. Over time I realised, however, that there was an absence of public consultation within the process of designing public spaces. Hence I shifted my interest from understanding the relationship between the natural and the built environment to focusing on exploring the symbiotic relationship between environmental conditions and people. 
According to González-Rey (2008), we have created an environmental system different from the natural one, which we called 'culture' and which 'operates on symbolic and emotional levels' (Calvo \& De Rosa 2017, 12). Culture, in this sense, acquires movement; it evolves in a socio-historical context and influences the designing of the built environment (Harvey 2012). In turn, culture shapes society and our lifestyle. Therefore, I am not the same person I was ten years ago. This is the result of a lifelong learning process. As Bateson (1972) states: 'the word learning undoubtedly denotes change of some kind. To say what kind of change is a delicate matter' (287). Recently, I have been learning how to use drawing in my reflections as an 'intuition pump' (Dennett 2013), in order to consolidate knowledge which emerges from situatedness. In tune with this, Creek (2007) states that reflection is an intuitive experience that enables understanding of ourselves within a context of practice. Over these ten years, my understanding of the world has shifted from a linear perspective into one in which everything is connected. As González-Rey (2014) reports, my personality is in movement, emerging from my situated experiences - where I am in play, interwoven with people's lives and the setting. This aligns with the concept of being developed by Heidegger (1949). I am what I am within my context.

\section{Reflective Drawing in the pilot study}

In this study the term reflective drawing refers to the use of drawing as a tool to support the research reflection process within an ethnographic approach to the field. This entails a successive cycle of reflections, each cycle comprises two stages: (i) first-order reflection conducted during the activity - although sometimes it is difficult due to the situatedness; and (ii) second-order reflection, after the activity to gather a descriptive account of what happened (Hammersley \& Atkinson 1995). For instance, collaborating in the consultation event during my third visit, I identified that some people felt uncomfortable when I took my notebook and started writing and drawing, so I took pictures as a way to affix certain moments (in my mind) and use them as 
decoys to recall the experience in a second-order reflection. Reflective drawing, here, is used to record data during fieldwork (i) enabling reflection-in-action, complementing field notes and disclosing visual and kinaesthetic learning and to recall the lived experience (ii), which helps to establish a bridge between theory and practice.

Reflective drawing, in the pilot study, emerged naturally during my first visit. One of my first drawings was a plan of the room made during the first co-design workshop. On it I drew the physical space, the furniture and the people. This helped me to understand the spatial dynamics in relation to the people. I found the space was too small to accommodate creative collaboration, as participants could not move freely, hindering spontaneous interactions beyond the limits of their chairs. I discovered that it took me less time to make sketches than writing, although I also took notes complementing the drawings. I drew rough lines creating the framework, capturing the instant and I finished them at home, in subsequent reflective sessions. These drawings are more than descriptive accounts of reality; they become selective visual narratives arisen from experience, through my eyes. After the workshop, I conducted the second stage of reflection (ii). I started writing and drawing what happened. I drew the participants capturing my impressions about their attitudes and while drawing I was analysing my memories.

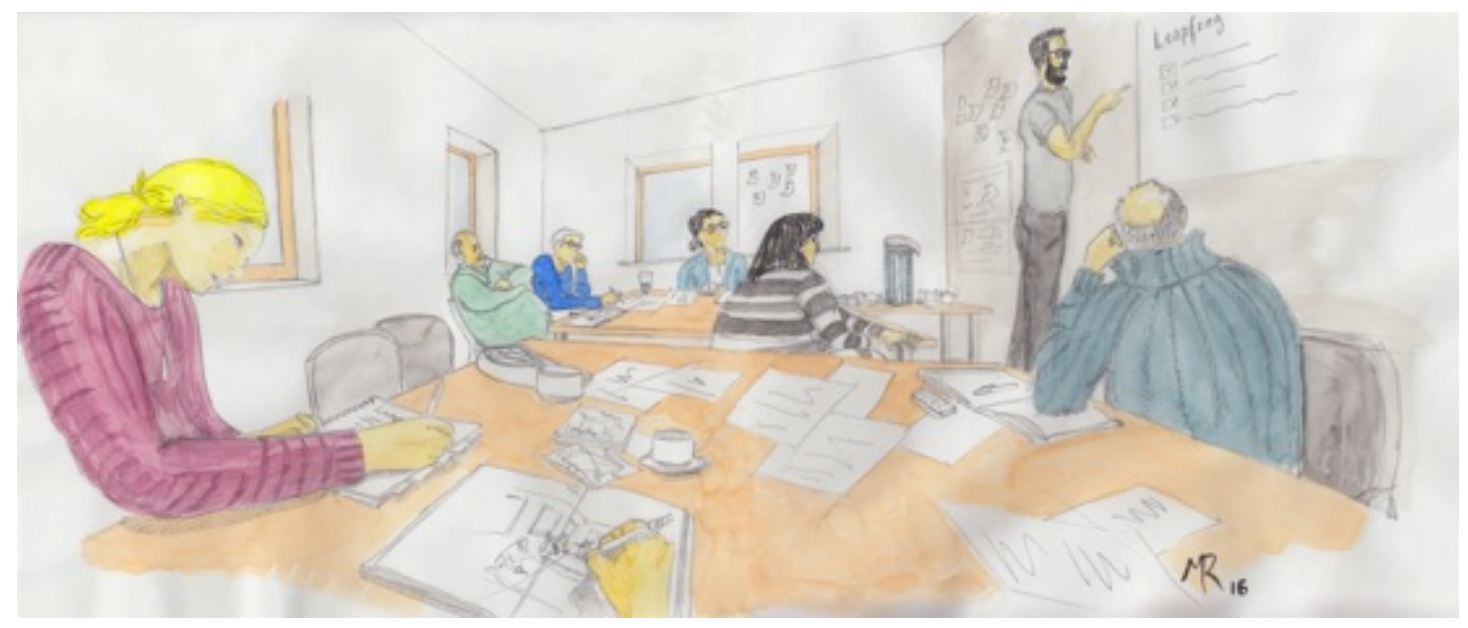

Figure 2. Author, Co-design workshop first-visit, 2016. 
In the second co-design workshop, I sketched the initial presentation where one designer was briefing the themes reached during the first workshop (figure 2). While drawing, I noticed that one of the participants sat in the same place as the previous day. He was leaning back in his chair and looking at the situation, apparently from a peripheral position. His attitude was subtly different from the rest; the others seemed to be fully focused on what the designer was saying and simultaneously relaxed. I noticed we all brought our notebooks and pens. This made me think that the participants came with the intention of learning something new. Some participants appeared to perceive designers as experts since they seemed to be 'acting' as the students. The participants appeared to give over all the power to the designer, assuming he was the expert - the teacher. Reflective drawing, in this stage (i), enabled me to visually put in relation the participants' attitudes (including designers). This observation made me realise that, in co-design, a horizontal power balance which is continuously negotiated by the participants - is required to establish a twoway conversation.

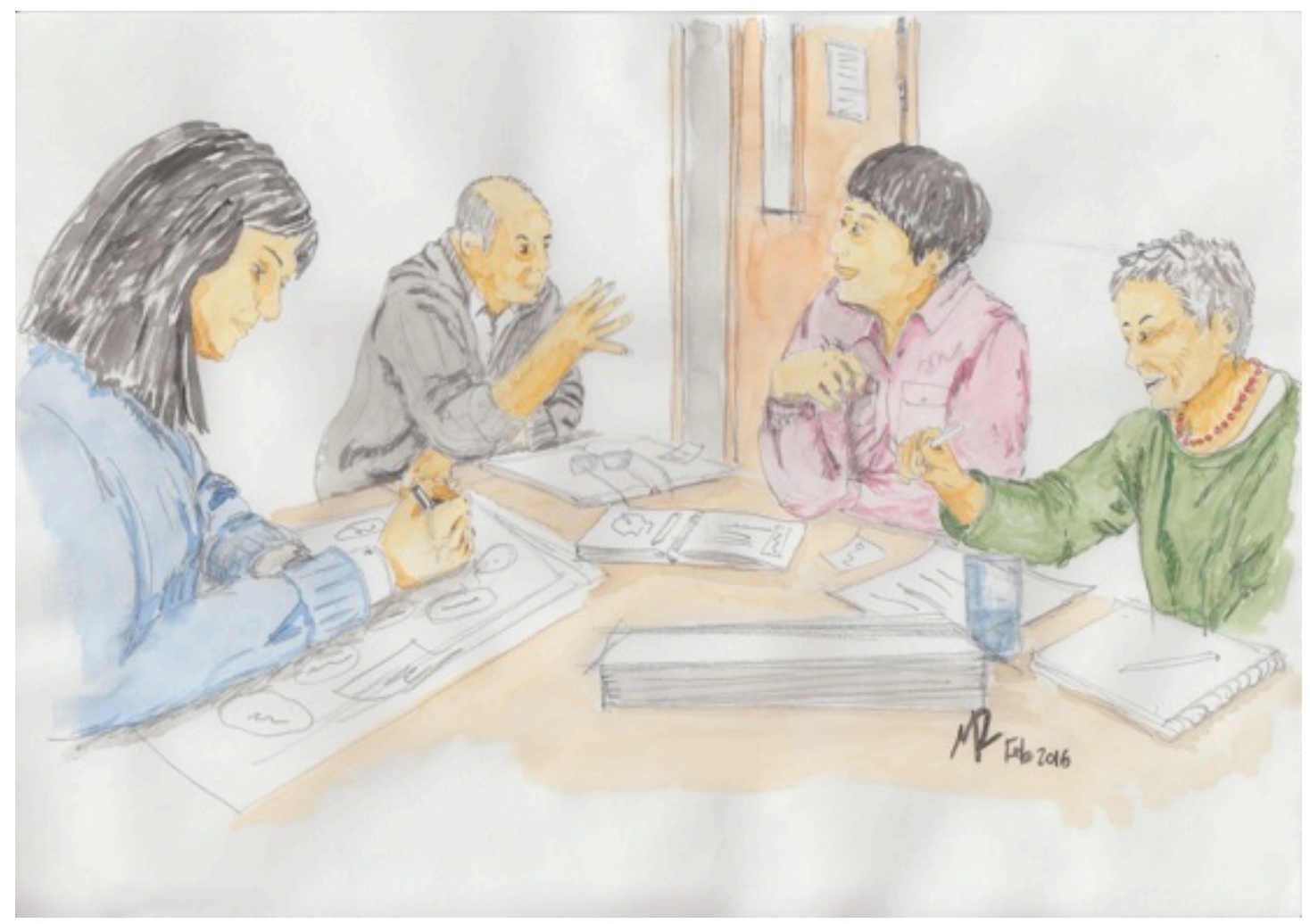


Figure 3. Author, Myself in the picture, 2016.

Back from the first visit, I went through my field notes and drawings in another reflective session (ii). These sessions are systematically done to step back and "ponder the meaning of what has recently transpired to us and to others' (Raelin 2001, 11), particularly relevant when using Grounded Theory as a way to inform subsequent steps and identify observational themes. I drew a scene in which I included two participants, the designer and myself (figure 3). The resulting drawing was a reconstruction elaborated upon primary data, where the reflective drawings made during the fieldwork (i) were used as prompts (by scrutinising them) to recall informal learning from experience, developing further understanding of the context and theorising new concepts. The act of drawing emerged as a tool to inquire into a series of vague and blurred ideas/impressions floating in my mind, as detached fragments that came together by drawing - revealing a visual piece of narrative. This drawing (figure 3) enabled to foreground the variety of attitudes and roles in my microcontext: the man was the strongest voice in our group - he was proactive and led the main conversation. The designer documented the dialogues with a calm and focused attitude, placing herself in a peripheral position within the conversation - avoiding the lead and providing room for the others to speak. The other participant spoke lesser in the main conversations and more in one-to-one's. Here I noticed that at the workshop there were multi-layered conversations and somehow they were related to a particular geographic location. I realised I did not know much about the participants' contexts (settings, background, culture, what community they belong or what they do for a living). I also realised that those interwoven conversations were also the vehicle for sharing knowledge. In a way, they were learning informally from each other but they were not aware, indeed, that I was learning too. Including myself in the picture was a way of reflecting on my position within the experience. I realised that I needed to accompany my actions according to the community process and leave room for adjustments and improvisation regarding group dynamics. New knowledge arose 
from this process, subjective knowledge (González-Rey 2014) or 'tacit knowledge' (Sanders \& Dandavate 1999) which 'embodies what is being voiced and articulated' (Neves 2014, 93) that, as Knight (1985) suggests, needs to be shared with others in order to be considered social knowledge, accepted by the community.

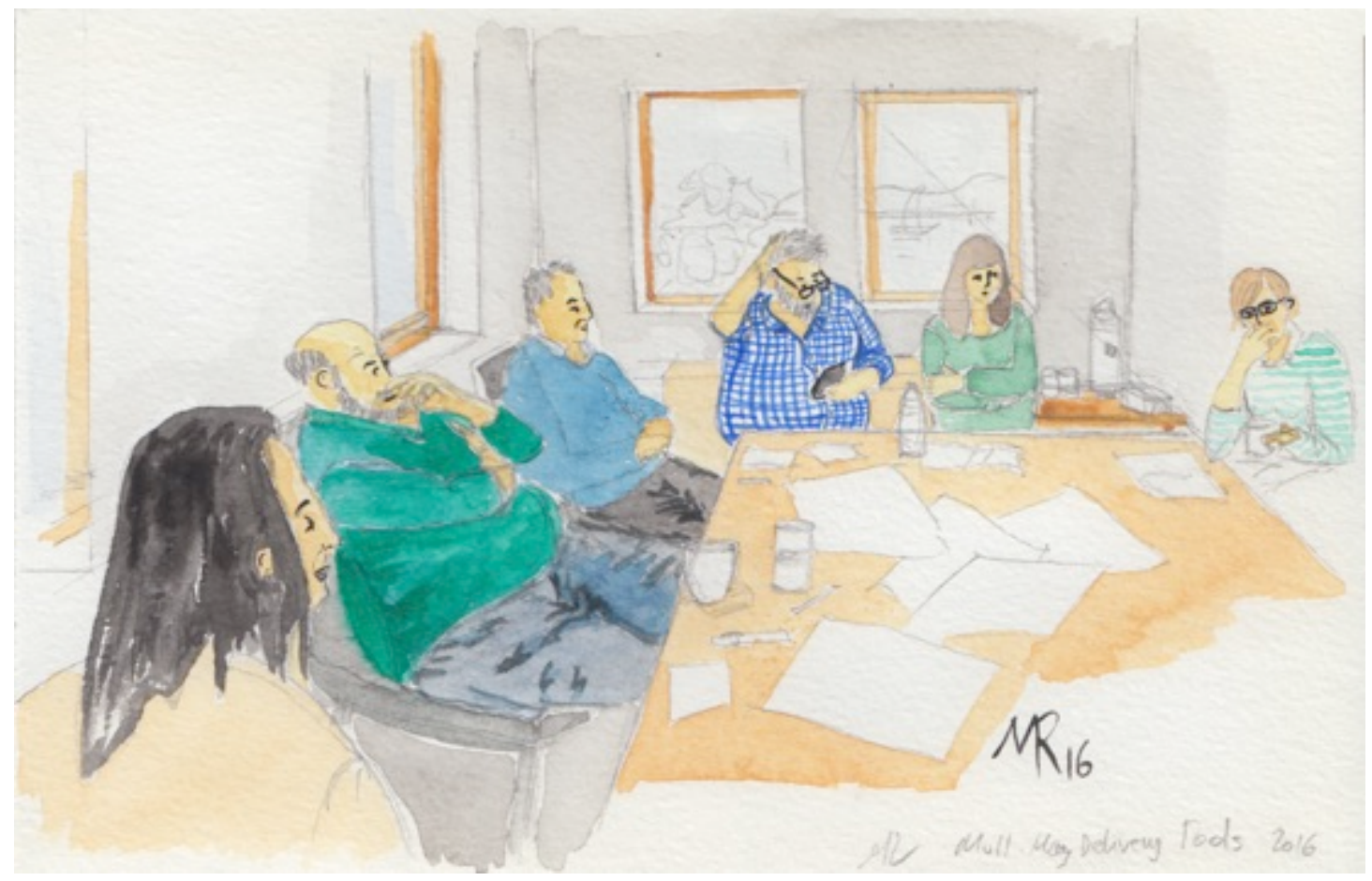

Figure 4. Author, Enabling Empathy, 2016.

Reflective drawing also helped me to establish a thread of empathy with participants. Empathy is part of the emotional intelligence that allows one to connect in a deeper and more emotional way with others. During the 'Tool-Sharing Event' I noted that by drawing the participants I was observing in-depth the details, connecting the parts and the whole (figure 4). Thus, through drawing I was, to some extent, attuned to their emotional state through detailed observation of their emotions that were reflected in their facial expressions, gestures and body language.

\section{Discussions}

This paper reports initial findings on an on-going $\mathrm{PhD}$ research project that aims to advance understanding in relation to the conscious use of drawing as a tool to support reflection and meaning making. The insights illustrated here suggest that reflection 
can be thought of as a method for connecting personal narratives with a higher scale of interaction in which the structures of power interweave with societal issues affecting personal everyday life. This leads designers to acquire a more holistic and self-aware grasp of the context of research, enabling them to learn from the settings and activities with which they are engaged. On the other hand, reflective drawing, I argue, is introduced as a vehicle to reflect and learn in a holistic manner, including more direct use of the senses, by integrating visual and kinaesthetic ways of learning (figure 5). Hence, reflective drawing helps to draw out the relationship between people and the meaning of the environment and helping to unpick emotional dynamics which through writing would be uneasy to identify.

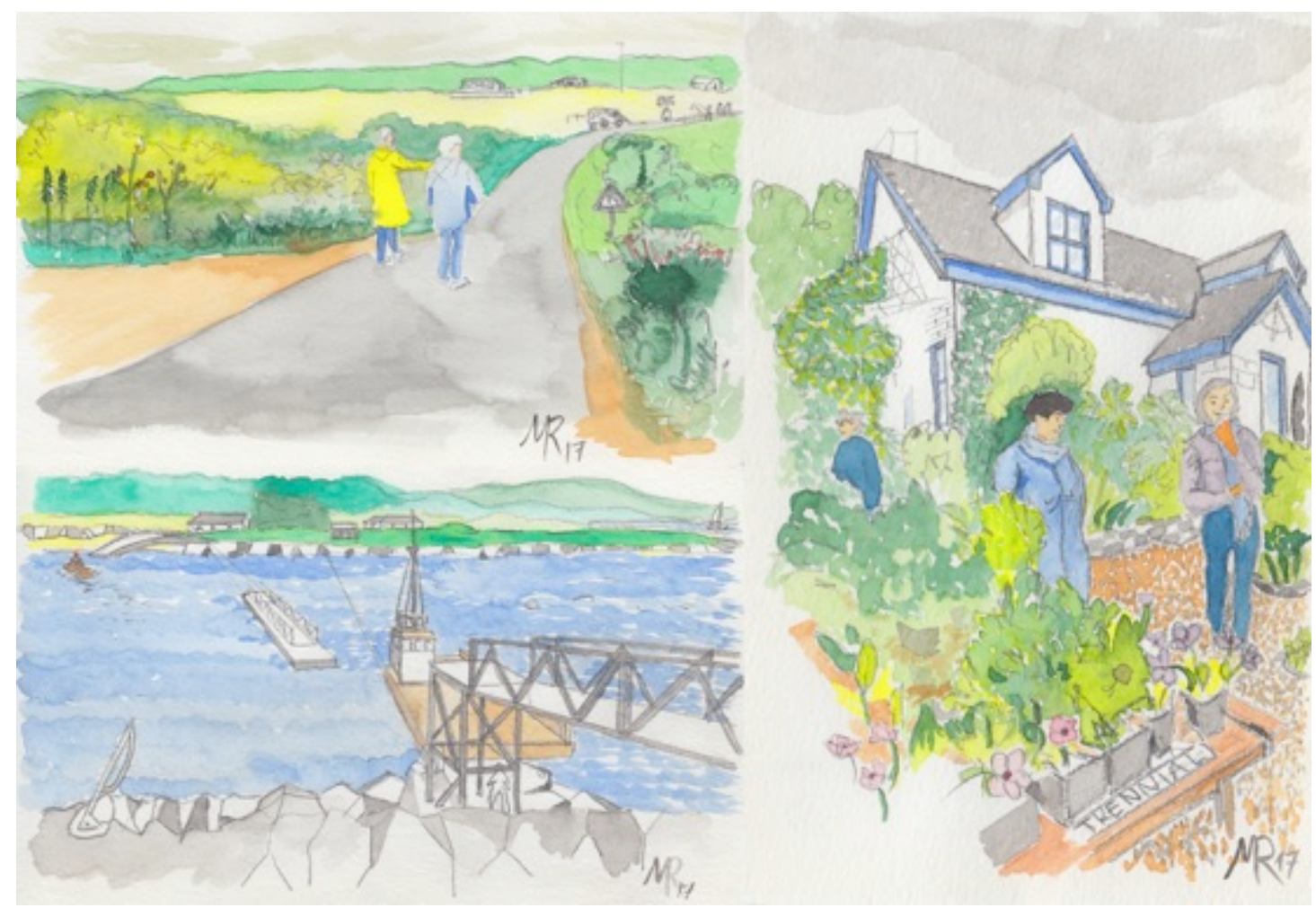

Figure 5. Author, Shadowing Participant 4: visual and kinaesthetic learning, 2017.

Any design process implies the use of iteration as a mechanism to redefine ideas and help in the process of materialisation into things - where things are understood as assemblies about 'matters of concern' (Boradkav, 2010; Latour, 2008). According to Stadil and Tanggaard (2014), creativity is in everyone's nature and it matures when we are able to create a social environment that supports it. They add that creativity 
happens at the edges of different landscapes of practices (see Wenger et al. 2015) and it requires practice and the development of habits, - opposing the dominant view that sees creativity as an instance of genius. They also emphasise that creativity and empathy are indivisible, one cannot exist without the other. On this matter, I would argue that reflective drawing can be considered a suitable tool able to fuse the processes of iteration and the reflection into one. This allows designers to put their creative skills to the service of participants and promote creative knowledgeexchange.

The next step will be the introduction of reflective practice to the participants of the next case study, a five-month-project which will involve myself as a researcher working alongside an interdisciplinary group of people coming from diverse social enterprises operating on the Highlands and Islands of Scotland. As Latour (2008) reports, drawing can become a powerful tool to put into play to foster innovative ways of co-constructing knowledge. His argument relies on the fact that drawing collectively can open up untapped ways of communication in community co-design by focusing on the conflicts and differences of interests. The idea, though, is to advance the argument that the impact of community co-design upon participants could be understood in terms of the informal-mutual learning process derived from engaging in such practices. People learn by participating, however they are not always conscious of this process. To foster self-awareness I have been working to develop a methodology that helps participants to fathom their informal-mutual learning through reflection as a way to promote critical thinking. Recognising what is happening helps people to process the co-production of emotions and symbols, and hence of subjective knowledge. Thus, while I seek to help participants articulate their own learning, I also aim to develop a systemic method that helps designers identify the impact and value of co-design upon participants and to some extent on their communities. Additionally, reflective drawing can generate data that emerges from the participants' eyes, rather than relying on designers to draw insight from the conversations. 


\section{References}

Andersen, N.E., Kensing, F., Lundin, J., Mathiassen, L., Munk-Madsen, A., Rasbech, M. \& Sørgaard, P. (1990) Professional Systems Development: Experience, Ideas and Action. Upper Saddle River, NJ: Prentice-Hall.

Bason, C. (2010) Leading Public Sector Innovation. Co-creating for a better society. Bristol: Policy Press.

Bateson, G. (1972) Steps to an ecology of mind. San Francisco: Chandler Pub. Co.

Blomberg, J. \& Karasti, H. (2013) Ethnography. Positioning ethnography within Participatory Design, in J. Simonsen \& T. Robertson [Eds] Routledge International Handbook of Participatory Design. New York: Routledg, pp. 86116.

Boradkav, P. (2010) Designing Things: A Critical Introduction to the Culture of Objects. Oxford: Berg.

Brandt, E., Binder, T. \& Sanders E. B.-N. (2013) Tools and techniques. Ways to engage telling, making and enacting, in J. Simonsen \& T. Robertson [Eds] Routledge International Handbook of Participatory Design. New York: Routledg, pp. 145-181.

Broadbent, J. (2003) Generations in design methodology, The Design Journal, Vol. 6, No. 1, pp. 2-13.

Calvo, M. \& De Rosa, A. (2017) Design for social sustainability. A reflection on the role of the physical realm in facilitating community co-design, in EAD12 (European Academy of Design), Design for Next. Rome, Italy, 12-14 April 2017.

Calvo, M., Sclater, M. \& Smith, P. (2016) Cultural-Historical Activity Theory and Informal Learning as a Key Component of Co-design Practice in a Community Initiative, in $8^{\text {th }}$ Triennial Conference ESREA (European Society of Research on the Education of Adults), Imagining diverse futures for Adult Education: 
Questions of power and resources of creativity. Maynooth University, Ireland, 8-11 September 2016.

Carroll, J.M. (2006) Dimensions of participation in Simon's design, Design Issues, Vol. 22, No. 2, pp. 3-18.

Creek, J. (2007) The Thinking Therapist, in J. Creek \& A. Lawson-Porter [Eds] Contemporary Issues in Occupational Therapy. Reasoning and Reflection. Chichester, West Sussex: John Wiley \& Sons Ltd, pp. 1-22.

Collier, P.J. \& Williams, D.R. (2013) Reflection in Action. The Learning-Doing Relationship, in C.M. Cress, P.J. Collier \& V.L. Reitenauer [Eds] Learning Through Serving: A Student Guidebook for Service-Learning and Civic Engagement across Academic Disciplines and Cultural Communities. Virginia, USA: Stylus Publishing LLC, pp. 83-95.

Corbin Dwyer, S. \& Buckle, J. (2009) The Space Between: On Being an InsiderOutsider in Qualitative Research. International Journal of Qualitative Methods. Vol. 8, No. 1, pp. 54-63.

Cross, N. (1972) Design Participation: Proceedings of the Design Research Society's Conference 1971. London: Academy Editions.

Cruickshank, L., Whitham, R. \& Morris, L. (2012) Innovation Through the Design of Knowledge Exchange and The Design of Knowledge of Knowledge Exchange Design, in International Design Management Research Conference: Leading Innovation through Design. Boston, MA, USA, 8-9 August 2012.

Dennett, D. (2013) Intuition pumps and other tools for thinking. New York: W.W. Norton \& Company, Inc.

Dewey, J. (1925) Experience and Nature. Chicago: Open Court Publishing Company. Dunbar, R. (1996) Grooming, Gossip and the Evolution of Language. Cambridge, MA: Harvard University Press.

Edwards, A. (2011) Building common knowledge at the boundaries between professional practices: Relational agency and relational expertise in systems of 
distributed expertise, International Journal of Educational Research, Vol. 50, pp. 33-39.

Engeström, Y. (1987) Learning by expanding: An activity-theoretical approach to developmental research. Helsinky: Orienta-Konsultit.

Er, M. (2014) Activity Theory, in D. Coghlan \& M. Brydon-Miller [Eds] The Sage Encyclopedia of Action Research 1. London: Sage, pp. 22-25.

Formenti, L. (2014) The myth of birth: autobiography and family memory, in L. Formenti, L. West \& M. Horsdal [Eds] Embodied Narratives. Connecting stories, bodies, cultures and ecologies. Odense: University Press of Southern Denmark, pp. 129-148.

Frith, U. \& Happé, F. (1994) Autism: beyond 'theory of mind', Cognition, Vol. 50, pp. 115-132.

Fuad-Luke, A. (2009) Design Activism: Beautiful Strangeness for a Sustainable World. New York: Earthscan.

Gaver, W., Boucher, A., Pennington, S. \& Walker, B. (2004) 'Cultural probes and the value of uncertainty', Interactions Vol. 11, No. 5, pp. 53-56.

González-Rey, F. (2014) Human Motivation in Question: Discussing Emotions, Motives, and Subjectivity from a Cultural-Historical Standpoint. Journal for the Theory of Social Behaviour, Vol. 45, No. 4, pp. 419-439.

González-Rey, F. (2008) Subjetividad Social, Sujeto y Representaciones Sociales [Social Subjectivity, Subject and Social Representations], Diversitas: Perspectivas en Psicología [Diversitas: Perspectives on Psycology], Vol. 4, No. 2, pp. 225-243.

Gutiérrez, K. (2008) Developing a Sociocritical Literacy in the Third Space. Reading Research Quarterly, Vol. 43, No. 2, pp. 148-164.

Hammersley, M. \& Atkinson, P. (1995) Ethnography: principles in practice. London: Routledge.

Harvey, D. (2012) Rebel cities: from the right to the city to the urban revolution. New York: Verso. 
Heidegger, M. (1949) Sein und Zeit [Being and Time]. Tübingen: Neomarius. Hodge, B. [Ed] (1998) Not Architecture But Evidence That It Exists: Lauretta Vinciarelli - Watercolors. New York: Princeton Architectural Press.

Humphrey, N. (1998) Cave Art, Autism, and the Evolution of the Human Mind. Cambridge Archaeological Journal, Vol. 8, No. 2, pp. 165-191.

Junker, B. (1960) Field Work. Chicago: University of Chicago Press.

Knight, S. (1985) Reflection and Learning: the importance of a listener, in D. Boud, R. Keogh, \& D. Walker [Eds] Reflection: Turning Experience into Learining. London: Kogan Page.

Kuutti, K. (2001) Activity Theory as a Potential Framework for Human-Computer Interaction Research, in B. Nardi [Ed] Context and consciousness: Activity theory and human-computer interaction. Cambridge: MIT Press, pp.1-22.

Labaree, R. (2002) The risk of 'going observationalist': negotiating the hidden dilemmas of being an insider participant observer, Qualitative Research, Vol.2, No. 1,pp. 97-122.

Latour, B. (2008) A Cautious Prometheus? A few steps toward a philosophy of design (with special attention to Peter Sloterdijk), in the Conference Design History Society, Networks of Design. Falmouth, Cornwall, 3-6 September 2008.

LeCompte, M.D. \& Schensul, J.J. (1999) Designing and Conducting Ethnographic Research, Ethnographers Toolkit, Vol. 1. Walnut Creek, CA: AltaMira Press

Lefebvre, H. (2003) La Révolution urbaine [The Urban Revolution]. Minneapolis: University of Minnesota Press.

Lee, Y. K. (2008) Design participation tactics: the challenges and new roles for designers in the co-design process, CoDesign, Vol. 4, No. 1, pp. 31-50.

Lektorsky, V.A. (2009) Mediation as a Means of Collective Activity, in A. Sannino, D. Harry \& K. Gutierrez, [Eds] Learning and Expanding with Activity Theory. Cambridge University Press, pp. 75-87.

Mithen, S. (1996) The Prehistory of the Mind. London: Thames \& Hudson. 
Neves, S. (2014) Enhancing the post-stroke patient experience at mealtime through participatory design: Eliciting, connecting and supporting multi-voicedness. $\mathrm{PhD}$ thesis, Glasgow School of Art.

Pallasmaa, J. (2017) Embodied and Existential Wisdom in Architecture: The Thinking Hand, Body and Society, Vol. 23, No. 1, pp. 96-111.

Pallasmaa, J. (2009) The Thinking Hand: Existential and Embodied Wisdom in Architecture. Hoboken, NJ: Wiley.

Raelin, J.A. (2001) Public reflection as the basis of learning, Management Learning, Vol. 32, No. 1, pp. 11-30.

Ryder, M. (2013) Activity theory. [Online] Available from: http://carbon.ucdenver.edu/ mryder/itc/activity.html [Accessed: 20th January 2017].

Salvador, T., Bell, G. \& Anderson, K. (1999) Design Ethnography, Design Management, Vol. 10, No. 4, pp. 35-41.

Sanders, E.B.-N. \& Dandavate, U. (1999) Design for experiencing: New Tools. [Online], available from: http://echo.iat.sfu.ca/library/sanders_99_newTools.pdf [Accessed: 20th March 2017].

Sanders, E.B.-N. \& Stappers, P. (2008) Co-creation and the new landscapes of design, CoDesign, Vol. 4, No. 1, pp. 5-18.

Schön, D. A. (1987) Educating the Reflective Practitioner. San Francisco, California: Jossey-Bass Inc., Publishers.

Selfe, L. (1977) Nadia: a Case of Extraordinary Drawing Ability in an Autistic Child. London: Academic Press.

Selfe, L. (1983) Normal and Anomalous Representational Drawing Ability in Children. London: Academic Pres.

Selfe, L. (1985) Anomalous drawing development: some clinical studies, in N.H. Freeman \& M.V. Cox [Eds] Visual Order: The Nature and Development of Pictorial Representation. Cambridge: Cambridge University Press, pp. 135-154. 
Silverman, R. M. \& Patterson, K. L. (2015) Qualitative Research Methods for Community Development. New York: Routledge.

Stadil, C. \& Tanggaard, L. (2014) In the Shower with Picasso. Sparking your Creativity and Imagination. London: LID Publishing Ltd.

Toadvine, T. \& Lawlor, L. [Eds] (2007) Cèzanne's Doubt, in The Merleau-Ponty Reader. Evanston, Illinois: Northwestern University Press.

Vygotsky L. (1978) Mind in society: The Development of Higher Psychological Processes. Cambridge, MA: Harvard University Press.

Wenger, E., Fenton-O’Creevy, M., Hutchinson, S., Kubiak, C. \& Wenger-Trayner, B. (2015) Learning in Landscapes of Practice. New York: Routledge.

Wenger, E., (1998) Communities of practice. Cambridge, UK: Cambridge University Press. 